\title{
Relationship of indicators of socio- psychological adaptation and characteristics of personal self-determination in students with special needs
}

\author{
Julia Selivanova ${ }^{1, *}$, Marina Konovalova $^{1}$, Elena Shchetinina $^{1}$ \\ ${ }^{1}$ Saratov State University, 83, Astrakhanskaya St., Saratov, Russia
}

\begin{abstract}
The article examines the correlation between the indicators of social and psychological adaptation of students with special needs and the characteristics of their personal self-determination. The average indicators of the primary scales in the questionnaire of social and psychological adaptation of students with special needs were calculated. The study established positive interrelationships between adaptability and meaningful indicators of personal self-determination, such as orientation towards maximum involvement in activities and emotional richness of life, confidence in one's abilities and the possibility to control the events of one's life. Self-acceptance as a component of socio-psychological adaptation positively correlates to the target indicators of personal self-determination, such as the meaningfulness of life, the presence of a goal in life and satisfaction with the results of self-determination. Internal control positively correlates to satisfaction with the results of self-determination. External (in relation to the personality) control as a component of socio-psychological adaptation negatively correlates to the assessment of energy, involvement, internal control, risk-taking as ways to overcome life's problems, and also to current life as an emotionally intense period of life. Submissiveness as a component of socio-psychological adaptation is negatively interconnected with the idea of a person's ability to control everything that is happening. Escapism (avoiding problems) negatively correlates to living an emotionally rich life, active participation and control as ways to overcome difficulties.
\end{abstract}

\section{Introduction}

The socio-psychological adaptation of students with special needs has repeatedly become the subject of research in psychology. This is connected both with the practical significance of the issue in current situation, namely, with the need to organize psychological support for such students in the university educational environment, and with the theoretical interest of researchers in the mechanisms of socio-psychological adaptation of a person with limited life resources. We understand the adaptive readiness of students with disabilities as having an attitude towards constructive interaction with the environment and a structure of

\footnotetext{
* Corresponding author: juliaselivanova@mail.ru
} 
psychological properties, qualities, and competencies relevant to this attitude. Student age is extremely rich and effective in terms of the processes of personal and professional selfdetermination and self-development. In our opinion, empirical data obtained in the analysis of the real practice of teaching university students with special needs play a huge role in solving the issues of search for patterns of personality development under a shortage of life resources.

Traditionally, the socio-psychological adaptation of a person to changing environmental conditions is considered from the point of view of the personality determinants of this process (A.A. Nalchadzhian, 1988 A.G. Maklakov, 2001, S.T. Posokhova, 2001, A.A. Rean, 2006). However, the social context can act as a key condition that triggers the process of personal self-development, especially in a situation of limited opportunities for life. As follows from A. Adler's idea, the dialectical transformation of organic inferiority into a desire for compensation and overcompensation is possible only through an assessment of one's social position. According to L.S. Vygotsky, in order to launch compensatory mechanisms, a future perspective and social orientation of these processes are needed [1].

Personal self-determination refers to the fundamental needs of both a maturing person and an already established person. Since personal transformations, as well as the variability of external factors accompany a person throughout their life, we can talk about both procedural and content characteristics of personal self-determination. In the study of the phenomenon of personal self-determination, we tried to integrate the provisions of the system-structural - B.G. Ananiev [2], subjective activity-related - K.A. AbulkhanovaSlavskaya [3], resource - R. Lazarus [4], S. Maddy [5], and existential - V. Frankl [6], E. Fromm [7] approaches to the study of human personality. The need to determine the meaning of life characterizes adult forms of behavior and therefore cannot be ignored when we are dealing with the process of personality maturation, the formation of the human "I". V. Frank1 considers the desire for a person to find and realize the meaning of their life as an innate motivational tendency inherent to all people which is the main driver of adult behavior and development. The studies of D.A. Leontiev, L.A. Alexandrova, A.A. Lebedeva established the relationship between the level of socio-psychological adaptation and personal resources of students in the context of inclusive professional education [8 - 12].

We have identified a complex of factors contributing to the process of self-determination of students with special needs: a feeling of complete involvement in activities; satisfaction with the process and the result of self-determination; self-confidence in managing one's own life and achieving success in implementing one's own plans. This complex of factors can be correlated with the results of other researchers and designated as internality. It is this factor that allows a person not only to make informed decisions in the process of self-determination and evaluate its results, but also to receive a feeling of fullness of vitality and possibilities: M.D. Konovalova [13], E.B. Shchetinina [14], J.V Selivanova [15].

In our study, we set the task to identify the interrelationships of indicators of sociopsychological adaptability and content characteristics of personal self-determination of students with special needs. Correlation research of this kind helps to establish the most essential personality determinants of the process of socio-psychological adaptation. Our research was based on the approach of A.L. Zhuravleva and A.B. Kupreychenko, who substantiate the identification of meaningful and formal-dynamic characteristics of personal self-determination [16].

\section{Research methods}

To assess the indicators of socio-psychological adaptation, we used the questionnaire of socio-psychological adaptation (SPA) by K. Rogers and R. Diamond adapted by A.K. Osnitsky. When assessing the meaningful indicators of personal self-determination, we 
thought it possible to correlate the target component of personal self-determination to the results obtained using the meaningful life orientation test by D.A. Leontyev; an indicator of assessing one's capabilities in the process of personal self-determination to the data of the scale of subjective vitality of R. Ryan and S. Frederick adapted by L.A. Alexandrova and D.A. Leontyev; ability to overcome problems to the results of the vitality test by S. Maddy adapted D.A. Leontiev and E.I. Rasskazova; satisfaction with the results of selfdetermination to the data of general self-efficacy scale by R. Schwarzer and M. Erusalem adapted by V.G. Romek. The search for the relationship of the studied characteristics was carried out using the Spearman's rank correlation coefficient (standard MS Excel package was used).

\section{Sample study}

The study involved 32 full-time first to final year bachelor and master students with special needs from Saratov State University. The majority (69\%) of the participants were female. The average age of the respondents is 20.5 years.

The study was carried out with the necessary adaptation of the stimulus material of psycho-diagnostic techniques for students with special needs. After receiving a consent to take part in the study, each participant was given a short interview and received instructions to work with the diagnostic package, in printed form if necessary. Visually impaired students received handouts printed in a larger font; blind participants filled out questionnaires taking instructions and questions by ear; their answers were entered into the form by an assistant.

\section{Results and discussion}

The data obtained in the questionnaire of social and psychological adaptation indicate a relatively high level of adaptation of the surveyed students. The average indicator on the scale "Adaptability" is $138.3+19.5$ points which exceeds the average standard indicator on this scale, the average integral indicator "Adaptation" is 67\%. Thus, in this sample, we are dealing with students whose average and high levels of socio-psychological adaptation prevail which makes it possible to correlate all the primary scales of the socio-psychological adaptation questionnaire to indicators obtained in the diagnosis of the content components of personal self-determination.

We identified positive relationships between the scale of adaptability in the questionnaire of socio-psychological adaptation with indicators of involvement $(r=0.68 ; p<0.01)$ and control $(\mathrm{r}=0.62 ; \mathrm{p}<0.01)$ of the vitality test and an indicator of the scale of general selfefficacy $(r=0.70 ; p<0.01)$. These data indicate that an important factor of adaptability is the confidence that everything that happens is assessed by a participant as really and potentially interesting, and active participation in activities brings pleasure. To achieve high adaptability of a person, confidence in the ability to influence the result of his activities is also necessary. And even if success is not guaranteed, then the range of effort should be proportional to the result obtained. It is not surprising, therefore, that trust in one's own capabilities, success in activities and the effectiveness of one's own efforts are closely interconnected with the adaptability of the individual. This conclusion is confirmed by the presence of significant negative correlation between the maladaptively scale of the socio-psychological adaptation questionnaire and the scales of involvement $(\mathrm{r}=-0.79 ; \mathrm{p}<0.01)$, control $(\mathrm{r}=-0.84 ; \mathrm{p}<0.01)$, risk taking $(\mathrm{r}=-0.72 ; \mathrm{p}<0.01)$ test of vitality, an indicator of the scale of dispositional vitality $(\mathrm{r}=-0.69 ; \mathrm{p}<0.01)$, as well as scales of meaningfulness of life $(\mathrm{r}=-0.63 ; \mathrm{p}<0.01)$, goals in life $(r=-0.69 ; p<0.01)$ and locus of control-I $(r=-0.62 ; p<0.01)$ in the test of meaningful life orientations. 
According to a number of researchers, one of the main "workarounds" for the development of the personality of adults with special needs is their ability to rely on their own positive assessment of their life, to comprehend it as a result of their activity, to make it a starting point and become more stable (L.A. Aleksandrova, A.A. Lebedeva, V.V. Bobozhei, 2013) This is confirmed by the numerous positive relationships which we have established between the indicator of self-acceptance of the socio-psychological adaptation questionnaire. In particular, such relationships were established with the scale of involvement of the vitality test $(\mathrm{r}=0.73 ; \mathrm{p}<0.01)$, as well as with most scales of the test of meaningful life orientations: with the scale of meaningfulness of life $(r=0.62 ; p<0.01)$, goals in life $(r=0.63 ; p<0.01)$, life process or emotional saturation $(r=0.65 ; p<0.01)$, life efficiency or satisfaction with self-realization $(r=0.61 ; p<0.01)$, locus of control $-\mathrm{I}(\mathrm{r}=0.65 ; \mathrm{p}<0.01)$. These data can be interpreted from perspective that the starting point in the self-determination of a person (both target, procedural and effective components) is a sufficiently high self-esteem of an individual which is supported by success in current activities and the presence of a sphere of self-expression. We believe that for the majority of students with special needs, it is the education process that presents the sphere of personally significant transformations, concentration and development of personal resources. Accordingly, the scale of selfacceptance negatively correlates to the scales of meaningfulness of life $(r=0.68 ; p<0.01)$, the life process or emotional saturation $(r=0.69 ; \mathrm{p}<0.01)$, the locus of control - I $(r=0.65$; $\mathrm{p}<0.01)$ in the test of meaningful life orientations, as well as with scales of involvement $(\mathrm{r}=$ - 0.66; $\mathrm{p}<0.01)$ and control $(\mathrm{r}=-0.73 ; \mathrm{p}<0.01)$ of vitality test.

Quite unexpected for us was the absence of significant correlations between the scale of acceptance of others from the questionnaire of socio-psychological adaptation and the scales of other questionnaires that characterize the process of personal self-determination. This probably indicates a decrease in the role of a significant other in making responsible life decisions at a student age. However, the scale of rejection of others in the questionnaire of socio-psychological adaptation has pronounced negative correlations with the scales of dispositional vitality $(\mathrm{r}=-0.61 ; \mathrm{p}<0.01)$, involvement $(\mathrm{r}=-0.73 ; \mathrm{p}<0.01)$, control $(\mathrm{r}=-$ $0.75 ; \mathrm{p}<0.01)$, risk taking $(\mathrm{r}=-0.62 ; \mathrm{p}<0.01)$ in the vitality test, also with scales "the process of life" or "emotional saturation" $(\mathrm{r}=-0.62 ; \mathrm{p}<0.01)$, and the locus of control - life $(\mathrm{r}=$ $0.61 ; \mathrm{p}<0.01)$ in the meaningful life orientation test. That is, successful self-determination is possible in a social environment that does not provoke aggression, intolerance, and pronounced conflicts.

The scales of emotional comfort and discomfort of the socio-psychological adaptation questionnaire did not reveal significant correlations with indicators of personal selfdetermination.

The study revealed a positive correlation of internal control scale in the questionnaire of socio-psychological adaptation with the scale of general self-efficacy $(r=0.71 ; p<0.01)$. This indicates that satisfaction with the self-determination process is interconnected with a sense of internal responsibility for the results achieved. Negative correlations of external control scale in the questionnaire of socio-psychological adaptation with indicators of dispositional vitality $(\mathrm{r}=-0.61 ; \mathrm{p}<0.01)$ in subjective vitality scale; scales of involvement $(r=-0.76 ; p<0.01)$, control $(r=-0.80 ; p<0.01)$, risk acceptance $(r=-0.70 ; p<0.01)$ in vitality test and scale of the process of life or emotional saturation $(r=-0.61 ; p<0.01)$ in meaningful life orientation test indicate that reliance on external circumstances and resources not directly related to their personality in the process of self-determination is unacceptable for the students with special needs.

The scale of dominance in the socio-psychological adaptation questionnaire did not reveal significant correlations with indicators of personal self-determination. The negative correlation of the scale "list" in the questionnaire of socio-psychological adaptation was revealed with the scale of control $(\mathrm{r}=-0.64 ; \mathrm{p}<0.01)$ in the vitality test, which probably 
indicates that an active desire to control everything is not consistent with the position of subordination in interpersonal contacts.

The scale of escapism (avoiding problems) in the socio-psychological adaptation questionnaire revealed negative correlations with the scale of the process of life or emotional saturation $(r=-0.60 ; p<0.01)$ in the test of meaningful life orientations and the scales of involvement $(\mathrm{r}=-0.75 ; \mathrm{p}<0.01)$ and control $(\mathrm{r}=-0.71 ; \mathrm{p}<0.01)$ in the viability test. These results indicate that avoiding problems is not a typical condition of students with special needs. They prefer a high level of involvement in activities, a desire to satisfy needs "here and now," focus on visible results of activity personally controlling whatever is happening.

\section{Conclusions}

Summing up the results of the analysis, we state that the socio-psychological adaptation of students with special needs is a complex and multidimensional process that requires active inclusion of many personal resources. Students with special needs characterized by a sufficiently high level of adaptation have the following characteristics of personal selfdetermination: they perceive their student age and the process of vocational training as extremely significant and emotionally rich, determined from the standpoint of its internal conditioning. It is also extremely important to be able to engage in intensive activity and understand personal responsibility for the results of one's own activity.

\section{Acknowledgements}

The article was prepared with the support of the Russian Foundation for Basic Research, the project "Personal self-determination and adaptive readiness of students with disabilities in an inclusive education" (No. 20-013-00534 A).

\section{References}

1. L.S. Vygotsky, Psychology of human development (Smysl. Eksmo, Moscow, 2005)

2. B.G. Ananiev, Personality, subject of activity, individuality (Direct-Media, Moscow, 2008)

3. K.A. Abulkhanova-Slavskaya, Activity and personality psychology (Nauka, Moscow, 2007)

4. R. Lasarus, Journal of Personality 1(74), 9 - 43 (2005)

5. S. Maddi, Psychological journal 6(26), 87 - 101 (2005)

6. V. Frankl, Psychotherapy and Existentialism. Selected Papers on Logotherapy (Institute of General Humanities Research, Moscow, 2015)

7. E. Fromm, Man for himself (AST, Moscow, 2009)

8. D.A. Leontiev, Siberian psychological journal 62, 18 - 37 (2016)

9. L.A. Aleksandrova, Psikhologicheskie Issledovaniya 3(17) (2011) http://psystudy.ru

10. D.A. Leontiev, E.I. Rasskazova, Test of vitality (Smysl, Moscow, 2006)

11. D.A. Leontiev, L.A. Alexandrova, A.A. Lebedeva, Personal development and psychological support for students with special needs in an inclusive professional education (Smysl, Moscow, 2017)

12. D.A. Leontiev, Cultural-Historical Psychology 3(10), 97-106 (2014) 
13. M.D. Konovalova, Izv. Saratov Univ. (N.S.), Ser. Educational Acmeology. Developmental Psychology 3(27), 220-227 (2018)

14. E.B. Shchetinina, M.D. Konovalova, Izv. Saratov Univ. (N.S.), Ser. Educational Acmeology. Developmental Psychology 3(2), 323-327 (2013)

15. J.V. Selivanova, T.V. Skliarova, Vestnik of Minin University 2(8) (2020) https://vestnik.mininuniver.ru/jour/index

16. A.L. Zhuravlev, A.B. Kupreychenko, Socio-psychological space of the individual (IP RAS, Moscow, 2012) 